\title{
Educação e tecnologia: entre o discurso e a prática
}

Ângela Carrancho da Silva"

\section{Resumo}

Este artigo apresenta uma reflexão sobre a inserção de tecnologia no cotidiano escolar. São analisados alguns resultados do Proinfo, relacionando-os às suas metas iniciais e aos atuais índices nacionais e internacionais de qualidade de educação. A análise dos indices revela que o investimento em tecnologia para a Educação Básica no país não garantiu a tão proclamada qualidade na educação brasileira. A conclusão aponta para a importância do papel do professor, a carreira de magistério em todos os seus aspectos, além de uma sérde outros fatores que podem contribuir para a efetiva inserção das TICs na prática pedagógica. As reflexões aqui descritas fazem parte dos trabalhos de pesquisa em Avaliação da Formação Continuada em Ambientes Virtuais de Aprendizagem, desenvolvidos na disciplina de Prática em Avaliação do Mestrado Profissional em Avaliação da Fundação Cesgranrio. As considerações apresentadas são fundamentadas em análises documentais e registros do cotidiano escolar.

Palavras-chave: Educação. Tecnologia. Inclusão digital. Politicas públicas.

\section{Education and technology: between discourse and praxis \\ Abstract}

This article presents a reflection on the integration of technology into everyday school life. Some Proinfo results are analyzed relating them to their initial goals and to the current national and international levels of quality of education. The analysis of the contents reveals that the investment in technology for Basic Education in the country has not ensured the much-vaunted quality to the Brazilian Education. The conclusion points out to the importance of the role of the teacher, the teaching career in all its

Doutora em Educação Ciência e Tecnologia, Universidade Estadual de Campinas (Unicamp);

Pesquisadora do Programa de Pós-Graduação em Avaliação da Fundação Cesgranrio.

E-mail: angelacarrancho@globo.com 
aspects, as well as a number of other factors that may contribute to the effective integration of ICT in pedagogical practice. The considerations described in this article are part of the research on Evaluation of Continuing Education in Virtual Learning Environments, developed in the discipline of Practice Evaluation in Professional Assessment Masters Program of Cesgranrio Foundation. The considerations presented are based on desk studies and records of the school routine.

Keywords: Education. Technology. Digital Inclusion. Public Policies

\section{Educación y tecnologia: entre el discurso y la práctica \\ Resumen}

Este artículo presenta una reflexión sobre la integración de la tecnología en la vida escolar cotidiana. Se analizan algunos resultados do Proinfo, en relación a sus objetivos iniciales y a los actuales indices nacionales e internacionales de calidad en educación. El análisis de los índices muestra que la inversión en tecnología para la Educación Básica en el país no garantiza la tan anunciada calidad en la educación brasileña. Como conclusión se señala la importancia del rol del profesor, la carrera de magisterio en todos sus aspectos, además de una serde otros factores que pueden contribuir para la efectiva integración de las TICs en la práctica pedagógica. Las reflexiones descritas integran la investigación en el marco de evaluación de la Formación Continuada en ambientes Virtuales de Aprendizaje, desarrollados en la asignatura de Práctica en Evaluación del Máster Profesional en Evaluación de la Fundación Cesgranrio. Las consideraciones presentadas se fundamentan en análisis documentales y registros de la vida cotidiana escolar.

Palabras clave: Tecnología. Proinfo. Educación Básica.

\section{Brasil: um país de muitos excluídos Os analfabetos}

Do vinil ao download

Do analógico ao digital

Do fogão a lenha ao micro-ondas

Da telefonia fixa ao telefone celular

De uma programação de 2 horas diárias à TV digital

Da Escola à escola: com ou sem tecnologia um retrato da mesmice

0 Rei está nu?

O Rei está nu!

0 Rei está nu. 
Os dados oficiais revelam que o analfabetismo no Brasil ainda é um dos piores da América Latina. 0 país ainda tem $9,6 \%$ da população com 15 ou mais anos analfabeta. A revelação está no Censo 2010, divulgado pelo Instituto Brasileiro de Geografia e Estatística (IBGE). Apesar da queda de quatro pontos percentuais - no Censo de 2000, o índice era de 13,6\% - quase 14 milhões de brasileiros (13.940.729) ainda não sabem ler nem escrever (IBGE, 2011).

Segundo análise da Pesquisa Nacional por Amostra de Domicílios (Pnad) de 2009, divulgada pelo Instituto de Pesquisa Econômica Aplicada (Ipea), a população brasileira apresentava uma elevada taxa de analfabetismo, inclusive quando comparada à de outros paises da América Latina, como Equador, Chile e Argentina (IPEA, 2010b). Entretanto, os dados mostram que houve uma redução deste número e que a queda da taxa tem sido constante desde o começo da década de 1990, fazendo esse índice recuar para cerca de 9,7\%, em 2009.

Entre 1992 e 2009, de acordo com o relatório, a taxa de analfabetismo foi reduzida em 7,5 pontos percentuais. 0 número total de analfabetos no Brasil, porém, permaneceu praticamente o mesmo nos últimos anos, girando em torno de 14 milhões de pessoas. Segundo definição internacional, o grau de analfabetismo de uma população é medido pela taxa de pessoas com 15 anos ou mais que não sabem ler e escrever um bilhete simples.

Segundo balanço da Unesco, o Brasil está ao lado de Egito, Marrocos, China, Indonésia, Bangladesh, Índia, Irã, Paquistão, Etiópia e Nigéria, como pais com mais de 10 milhões de analfabetos. A Pnad aponta que em 2006 o Brasil tinha 14,9 milhões de pessoas não sabiam ler nem escrever. No Brasil o analfabetismo está concentrado entre os mais pobres, mais idosos, negros ou pardos (terminologia ainda utilizada pelo IBGE) e em áreas mais pobres. A Pnad mostra que dos analfabetos, 67,4\% eram negros ou pardos, enquanto 32\% eram brancos (IPEA, 2010b).

0 quadro do analfabetismo funcional não difere muito, já que, também de acordo com os dados do IBGE (2011), o Brasil tem 33 milhões de analfabetos funcionais (cerca de 18\% da população), ou seja, pessoas com menos de quatro anos de estudos, e 16 milhões de pessoas com mais de 15 anos que ainda não foram alfabetizadas.

\section{Os analfabetos digitais}

As tecnologias da informação, junto com a habilidade para usá-las e adaptá-las, são o fator crítico para gerar e possibilitar acesso à riqueza, poder e conhecimento no nosso tempo. (Manuel Castells)

As novas tecnologias digitais da informação e da comunicação, de leitura e escrita, têm produzido uma série de mudanças tanto na natureza do letramento, quanto na comunicação na sociedade contemporânea. Desta forma, as novas práticas sociais de 
leitura e escrita se constituem no que é denominado hoje de letramento digital. Buzato ([2003], não paginado) define o letramento eletrônico como "o conjunto de conhecimentos que permite às pessoas participarem nas práticas letradas mediadas por computadores e outros dispositivos eletrônicos no mundo contemporâneo". Silveira (2001) também afirma que a comunicação na sociedade pós-moderna pressupõe a interação nas redes de informação e que "a maioria da população, ao ser privada do acesso à comunicação mediada por computador, está sendo simplesmente impedida de se comunicar pelo meio mais ágil, completo e abrangente". Para o autor, a "cidadania eletrônica" demanda o direito de acesso e compartilhamento das redes de comunicação e informação como condição fundamental para o letramento digital.

É possível afirmar, portanto, que o letramento digital é a capacidade que o indivíduo tem de responder adequadamente às demandas sociais que envolvem a utilização dos recursos tecnológicos e da escrita no meio digital. Importante é também ressaltar que, para a plena conquista da cidadania na sociedade contemporânea, o indivíduo deve ter acesso às ferramentas digitais. Ter acesso à tecnologia é o passo inicial para combater a exclusão digital que ainda atinge um grande contingente de indivíduos no Brasil já que, com relação ao analfabetismo tecnológico, a situação não difere muito do quadro de analfabetismo como um todo no país. Entretanto, é preciso destacar que esse conceito está diretamente ligado ao que muitos autores chamam de exclusão digital, enfatizando que o foco é o cidadão digital e tecnologicamente excluído ou infoexcluido, mas que precisa ter a chance de ser incluído na sociedade da informação. Cabral Filho $(2006$, p. 111) afirma que

a inclusão digital se assemelha, portanto, à ideia de alfabetização digital, numa equivalência com a perspectiva da alfabetização no processo de inclusão social, voltando o foco para aqueles que também se encontram no próprio contexto de exclusão social, acrescentando a temática da tecnologia digital no sentido de somar esforços para atenuar essa diferença.

É inegável que a exclusão digital tem uma imensa correlação com outras formas de desigualdade social e, de forma geral, as maiores taxas de exclusão se encontram nos setores de mais baixa renda. Autores como Rezende (2005) e Sorj (2003) afirmam que a desigualdade social no campo das comunicações, na sociedade de consumo de massa, é expressa tanto pela capacidade de acesso ao bem material como - rádio, telefone, televisão, internet -, quanto pela capacidade que o usuário possui de retirar o máximo proveito possível das potencialidades oferecidas por cada instrumento de comunicação e informação.

Em se falando de Brasil, um país continente com enorme desigualdade social, o problema da exclusão digital se torna ainda mais grave, como afirma Demo (2005, não paginado): 
[...] é problema agudo de países atrasados, mas acomete também vastas camadas em países avançados, porque muitos adultos/idosos não se propõem mais inserir-se na sociedade digital com autonomia. Usam produtos digitais como consumidores (da nova mídia, por exemplo), mas não se dispõem mais a desenvolver habilidades digitais de manejo próprio. Interessa-nos aqui a discriminação digital contra imensos segmentos sociais pobres, situação em geral agravada pela má qualidade da escola pública.

0 problema do analfabetismo, no Brasil, precede o da inclusão digital. Os indices de analfabetismo são alarmantes assim como o são os índices de exclusão social e digital de grande parte da população brasileira. Destaca-se, ainda, que há diferenças imensas entre o Norte e o Sul do pais, entre brancos e negros, entre homens e mulheres; enfim, seria possivel continuar enumerando uma sérde segmentos da população que se encontram no mundo dos excluidos brasileiros. 0 grande contingente de analfabetos e de comunidades carentes, isoladas e sem acesso às necessidades básicas, tais como alimentação, transporte, moradia, água, luz, entre outros, provoca uma distorção entre o que estas comunidades precisam e o que a Escola Pública tem para oferecer. Por mais que a Educação, por meios de seus gestores em nivel federal, estadual e municipal, muitas vezes, busque para si o papel de "salvadora da pátria", ela não será capaz, por si só, de diminuir o "fosso" entre os incluidos e os excluídos. Entretanto, também se sabe que entre os determinantes da desigualdade de renda no país, a educação tem se destacado, desde os anos 70, como o mais importante (LANGONI, 1973; FISHLOW, 1973; BARROS; HENRIQUES; MENDONÇA, 2000; HOFFMANN, 2000; RAMOS; VIEIRA, 2001). Neste sentido, Hoffmann (2000) afirma que, embora as estimativas possam não ser perfeitas, a educação é sem dúvida um dos principais determinantes da renda dos indivíduos, constituindo um caminho clássico de ascensão social, ou seja, de inclusão e exclusão social.

É importante destacar que, apesar das discordâncias sobre o papel da educação na redução da desigualdade, há consenso de que a promoção do ensino básico no país é condição fundamental para o exercício pleno da cidadania e para a participação adequada das pessoas na sociedade contemporânea. Mesmo autores como Fishlow (1973), Hoffmann (2000) e Ueda (2001), que apontam para a possibilidade da existência de certo exagero na avaliação dos efeitos da variável educação, acreditam que o nivel educacional é um dos principais indicadores da concentração da renda no país. Para Fishlow (1973, p. 45), por exemplo, embora houvesse, na década de 1970, um exagero no nivel de desigualdade explicado pela educação, ele não deveria "significar o desprezo pela política educacional, um instrumento sempre muito importante em qualquer estratégia de diminuição da desigualdade de renda". 
Exageros à parte é evidente que, - a partir dos resultados das pesquisas apresentadas e de uma sérde outras -, mesmo não sendo determinante, a educação é fator de inclusão ou exclusão social. De acordo com os dados da Pnad de 2007 (IBGE, 2007), para um total de jovens brasileiros entre 17 a 19 anos de idade, pertencentes ao grupo dos mais ricos, 95,1\% conseguiram concluir o ensino fundamental; o percentual, no grupo dos mais pobres, cai para 55,6\%. Enquanto os jovens do primeiro grupo têm muita chance de ingressar no ensino médio, boa parte do segundo grupo fica restrito ao ensino fundamental, o que, com certeza, contribui para gerar heterogeneidade educacional entre as pessoas que ingressam no mercado de trabaIho e, consequentemente, engrossar as estatísticas da exclusão social.

No que diz respeito ao acesso à tecnologia, um quadro muito parecido pode ser observado no país. Apesar do crescimento do acesso à internet de mais de $100 \%$ entre os anos de 2000 e 2005, o país ainda possui uma baixa parcela da população que usufrui os benefícios dos recursos da rede. É possível também verificar pelas pesquisas (SORJ, 2003; NEY, 2006; NEY; SOUZA; PONCIANO, 2010) que os determinantes da exclusão social estão presentes também na exclusão digital. Por exemplo, o acesso à internet tem uma relação diretamente proporcional aos niveis de educação e renda. As menores percentagens de presença na rede são encontradas entre as pessoas que estão fora da escola e do mercado de trabalho. Na mesma direção é possível constatar que os Estados e Regiões Geográficas com os maiores Índices de Desenvolvimento Humano (IDH) são também aqueles com maiores níveis de acesso à internet.

Portanto, a formulação de políticas públicas capazes de contribuir para a aceleração do processo de inclusão digital que visem ao avanço da inclusão digital e à consequente inclusão social em todos os seus aspectos e para todos os brasileiros deveria ser a prioridade de um estado que pretende diminuir as distâncias sociais existentes no país e garantir o acesso democrático aos bens de consumo aos cidadãos, minimizando a exclusão tanto digital quanto social de um grande contingente de brasileiros.

\section{Políticas brasileiras de educação e informática: o Proinfo}

0 momento não é mais de defender ou não o uso de computadores em salas de aula. A informática está aí, chegou a muitas escolas, a outras não, apesar das várias iniciativas de inserção das Tecnologias de Informação e Comunicação (TIC) no cotidiano escolar realizadas pelo Ministério de Educação (MEC) a partir da década de 1980 do século passado. Por meio de uma análise das políticas públicas neste setor, é possivel notar as muitas idas e vindas, avanços e retrocessos marcados por portarias, decretos, programas, conselhos e orçamentos criados, cancelados e, em alguns casos, reestruturados e criados novamente. As políticas adotadas pelos governos que passaram por este período demonstram a consciência de que o país não pode 
ficar ausente de uma política que integre as Tecnologias de Informação e Comunicação à Educação, mas contraditoriamente, também é possivel perceber a ausência de uma política ampla, duradoura e consistente neste sentido.

Segundo informações contidas no site oficial da Secretaria de Educação a Distância (SEED), o Programa Nacional de Tecnologia Educacional (Prolnfo), inicialmente denominado Programa Nacional de Informática na Educação, foi criado pelo Ministério da Educação, pela Portaria no 522 (BRASIL, 1997b), com a finalidade de promover o uso da Telemática como ferramenta de enriquecimento pedagógico no ensino público fundamental e médio. Na década passada os números apresentados pelo Proinfo já eram alvissareiros. Dois governos se passaram e as metas ficaram muito aquém do esperado tanto em termos quantitativos quanto na esfera qualitativa.

De acordo com o Projeto do Proinfo, disponibilizado pela SEED/MEC, os objetivos deste Programa são:

1. Melhorar a qualidade do processo de ensino-aprendizagem [...];

2. Possibilitar a criação de uma nova ecologia cognitiva nos ambientes escolares mediante incorporação adequada das novas tecnologias da informação pelas escolas [...];

3. Propiciar uma educação voltada para o desenvolvimento científico e tecnológico [...];

4. Educar para uma cidadania global numa sociedade tecnologicamente desenvolvida [...] (BRASIL, 1997c, p. 7).

Ainda de acordo com o mesmo documento, o Proinfo foi criado para atender todas as escolas da rede pública de ensino de todos os estados brasileiros, por meio da colaboração entre o MEC e as demais esferas governamentais estaduais e municipais. 0 sucesso do Programa dependeria fundamentalmente da capacitação dos recursos humanos envolvidos em sua operacionalização, principalmente os professores.

Conforme as metas iniciais do Proinfo, sua implementação aconteceria de forma descentralizada, respeitando as peculiaridades de cada Estado, num ambiente de interação viabilizando uma sérde beneficios, dentre os quais se podem destacar os seguintes:

1. a melhoria da qualidade e eficiência do sistema educacional público brasileiro;

2. o baixo custo dos investimentos, correspondente a US\$ 72.00 por aluno beneficiado, já incluida a montagem de infraestrutura de formação e custeio de profissionais por dois anos;

3. o acesso de alunos de menor poder aquisitivo a recursos tecnológicos, possibilitando-lhes uma inserção mais vantajosa no mercado de trabalho; 
4. a geração direta e indireta de empregos (mormente no setor serviços);

5. a difusão da informática em novos mercados consumidores, pelo evidente efeito demonstração nas "vitrines escolares";

6. contribuição para o revigoramento e a mudança de perfil de economias locais, mediante formação de recursos humanos melhor capacitados;

7. a utilização dos equipamentos pelas comunidades, inclusive em cursos específicos de interesse da vocação econômica local;

8. melhoria da gestão escolar;

9. acesso a redes de informações globais (internet). (BRASIL, 1997c, p. 19).

Com relação ao Acompanhamento e Avaliação do Programa, o documento indica que seriam contemplados indicadores como: "indices de repetência e evasão; habilidades de leitura e escrita; [...] desenvolvimento das habilidades de trabalho em equipe; [...] o acesso à tecnologia por alunos de classes socioeconômicas menos favorecidas [...]" (BRASIL, 1997c, p. 11).

Uma análise dos índices referentes à qualidade de educação no país indica que as metas originais do Proinfo, no que tange à promoção da melhoria da qualidade ensino no pais, estão longe de ser atingidas. De acordo com os resultados do Índice de Desenvolvimento da Educação Básica (Ideb) criado pelo Inep, em 2007, e publicados pelo MEC, em 2010, revelam que, apesar da melhoria do país nos resultados, 24\% dos municipios ficaram abaixo da meta estipulada para 2009 (BRASIL, 2010). No ensino médio, o estudo aponta que Roraima, Piauí, Sergipe, Espírito Santo e Rio de Janeiro tiveram resultado negativo com relação às metas estipuladas para 2009. Os outros estados atingiram a meta ou superaram a nota. A pior nota estadual é a do Piauí, que atingiu a nota 3, e cuja meta era 3,1. Em 2005 e 2007, o estado atingiu 2,9. A escala vai de 0 a 10.

No Ensino Médio, as escolas fluminenses tiveram o segundo pior resultado do país, atrás apenas do Piauí. Já na avaliação entre as $5^{\mathrm{a}} \mathrm{e} 8^{\mathrm{a}}$ séries, o estado ficou em $21^{\circ}$ lugar no ranking entre os 26 estados do país. 0 resultado melhora um pouco da $1^{\text {a }}$ à $4^{\text {a }}$ série, em que o Rio aparece no $18^{\circ}$ lugar. Da $1^{\text {a à }} 4^{\text {a }}$ série, houve um avanço de 3,8, registrados em 2007, para 4 pontos em 2009 - menos do que a meta, que era de 4,1. 0 desempenho foi ainda pior entre os alunos da $5^{a}$ à 8 série, já que 0 número também aumentou pouco: de 2,9 para 3,1. Segundo os dados, os resultados não tiveram alterações no Ensino Médio, em que os alunos ficaram, em média, com os mesmos 2,8 de 2007, abaixo da meta do MEC, que era de 2,9. Para chegar ao índice, o ministério leva em conta fatores como: taxas de aprovação e reprovação, percentual de abandono escolar e desempenho na Prova Brasil. 
Ainda com relação à qualidade de ensino, como aponta o Gráfico 1, retirado do relatório "Monitoramento de Educação para Todos 2010", lançado pela Organização das Nações Unidas para a Educação, Ciência e Cultura (Unesco),

o Brasil apresenta alta repetência e baixos índices de conclusão da educação básica. [...] Na região da América Latina e Caribe, a taxa de repetência média para todas as séries do ensino fundamental é de 4,4\%. No Brasil, o índice é de $18,7 \%$, o maior de todos os países da região.

[...] 0 país ocupa a $88^{\text {a }}$ posição em um ranking de 128 países. Em 2000, mais de 160 países assinaram o compromisso Educação para Todos, que previa o cumprimento de seis metas incluindo a universalização do ensino fundamental, a redução da taxa de analfabetismo e a melhoria da qualidade do ensino. Para isso, criou-se um o Índice de Desenvolvimento de Educação para Todos (IDE) (RELATÓRIO..., 2010, não paginado).

Como é possível observar, apesar da criação de vários índices para garantir a qualidade de ensino, ainda estamos muito longe de atingi-la, seja com ou sem a inserção de tecnologia em nossas salas de aula.

Gráfico 1: Qualidade do ensino no país.

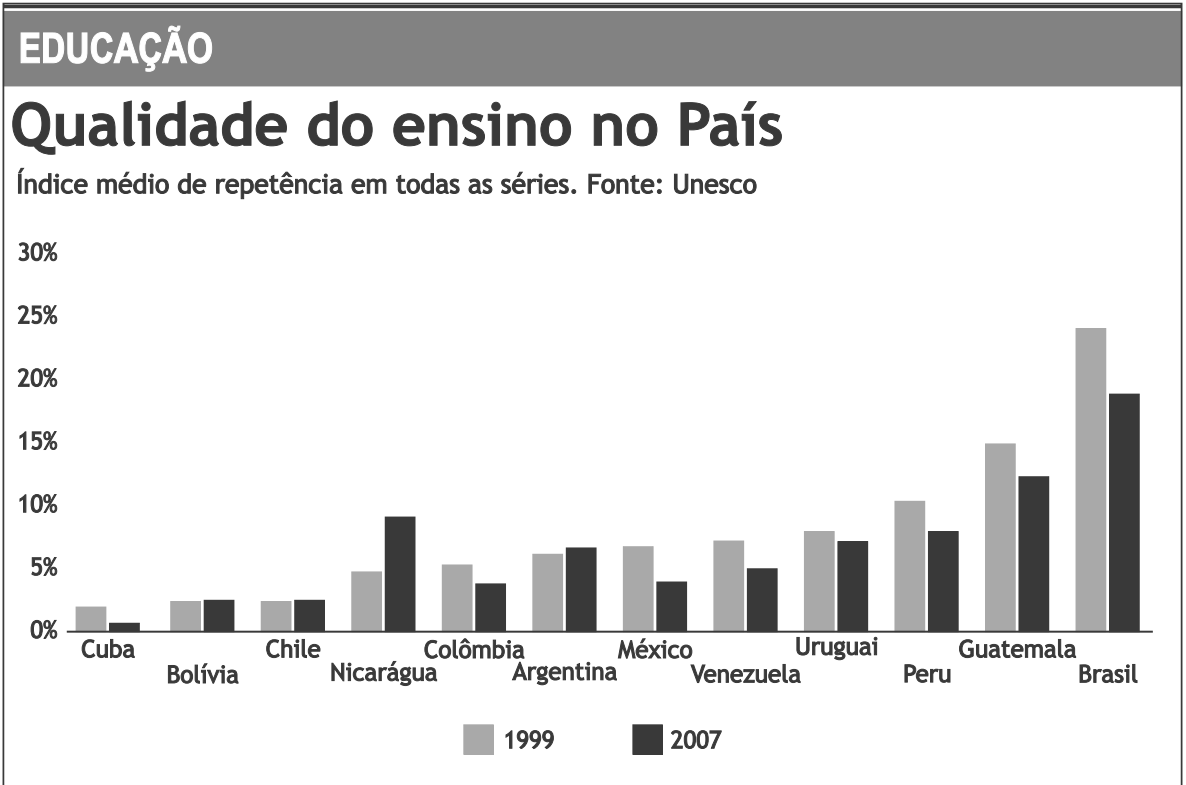

Fonte: Unesco (2010). 
No que tange à utilização pedagógica dos computadores no cotidiano escolar, estudos como os de Oliveira (2001), Cysneiros (2003), Souza (2003), Campos (2004), Ronsani (2005) e Silva (2007) consideram o uso dos laboratórios de informática insignificante em função do número insuficiente de máquinas e também pela falta de conservação e manutenção do funcionamento dos equipamentos e dos softwares.

Com relação à quantidade e às dimensões dos laboratórios do Proinfo, autores como Oliveira (2001), Cysneiros (2003), Fernandes (2003) e Silva (2005) os conside-

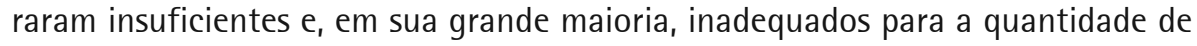
alunos matriculados por turma nas escolas públicas brasileiras.

0 Proinfo tinha como uma de suas metas prioritárias a formação continuada de professores. Entretanto, em estudos como os de Abranches (2003) Salazar (2005) e Passos (2006) é possivel perceber que a falta de continuidade, além da pequena carga horária da maioria dos cursos, contribuiu para o descrédito dos mesmos no ambiente escolar. Outro aspecto destacado por estes pesquisadores foi o teor tecnicista dos cursos, que frequentemente abordavam apenas a utilização do pacote Windows, sem apresentar qualquer software pedagógico ou apontar as possiveis utilizações do computador a partir dos conteúdos curriculares.

Hobold (2002), Quartiero (2002), Abranches (2003) e Moraes (2006) afirmam que a falta de tempo e disponibilidade dos professores para frequentar os cursos, assim como a resistência em inserir o computador em sua prática pedagógica também podem ser considerados aspectos importantes para a subutilização dos computadores no cotidiano escolar. Os mesmos autores chamam atenção também para o número insuficiente de professores-formadores necessários para a continuidade da formação em serviço.

De acordo com o Censo Escolar de 2010 (INEP, 2010), o pais possui 42,9 milhões de alunos matriculados na rede pública. Os dados revelam ainda que o sistema escolar tem quase o dobro de alunos no primeiro segmento do ensino fundamental quando comparados aos dados do ensino médio. Os dados do Censo 2010 registraram 13,4 milhões de matrículas nos anos iniciais do Ensino Fundamental ( $1^{\circ}$ ao $5^{\circ}$ ano; com crianças a partir dos 6 anos) e 7,1 milhões de matrículas no ensino médio ( $1^{\circ}$ ao $3^{\circ}$ ano). Pode-se constatar, portanto, por meio dos dados oficiais, que a implementação do Proinfo, em âmbito nacional, ainda é incipiente.

Em síntese, é possível verificar que o Proinfo tem sido implementado de forma fragmentada e descontínua. No que diz respeito às instalações, na maioria das unidades escolares os laboratórios são inadequados e o número de computadores sempre insuficiente para o quantitativo de alunos em sala de aula. Os cursos organizados para os professores têm sido considerados, pelos próprios professores, como precários, principalmente quando se avalia a carga horária e o conteúdo tecnicista da grande maioria dos cursos a eles oferecidos. 
É evidente que muitas das metas do Proinfo foram cumpridas; entretanto, a sua meta principal esta longe de ser atingida: nenhum pais com 14 milhões de analfabetos está "propiciando uma educação voltada para o desenvolvimento científico e tecnológico, e para uma cidadania global numa sociedade tecnologicamente desenvolvida".

Os Núcleos de Tecnologia Educacional (NTE), por serem uma estrutura federal encravada em escolas estaduais e municipais, ficaram, muitas vezes, sem a sua total capacidade de atuação já que há diferenças profundas entre as três esferas de governo. Desta forma, muitos de seus objetivos deixaram de ser alcançados.

É possivel, a partir dos dados apresentados sobre o Proinfo, suspeitar que a inserção do computador no cotidiano escolar brasileiro vem servindo de moeda de troca eleitoral já que a informatização das escolas públicas continua sendo uma das metas previstas no Plano de Desenvolvimento da Educação (PDE), lançado pelo governo federal (BRASIL, 2007b). 0 governo federal instituiu uma política pública determinando que, até 2010, todas as escolas públicas do país tenham um laboratório de informática, com no mínimo dez microcomputadores com acesso gratuito à internet em alta velocidade.

Mais uma vez, é possível constatar que, apesar da ousadia das metas, as evidências cotidianas indicam que esta é apenas mais uma fala de efeito uma vez que um número muito grande de escolas públicas brasileiras se encontra, por exemplo, sem possibilidade de acesso à banda larga. De acordo com o publicação do Instituto de Pesquisa Econômica Aplicada (Ipea), há um profundo desequilíbrio e baixa concentração da banda larga em diversos Estados brasileiros (IPEA, 2010a). 0 documento destaca ainda que a banda larga está presente em apenas 2.583 dos 5.565 municípios. Isso significa 46,6\% do número total de municípios brasileiros, embora neles se concentrem mais $80 \%$ da população do país.

Para melhor compreender a importância do acesso à banda larga para o cotidiano escolar, em novembro de 2007, o jornal 0 Estado de São Paulo publicou os resultados de um levantamento elaborado por Roberta Bioi e Fabiana de Felício (apud PARAGUASSÚ, 2007), técnicas do Instituto Nacional de Estudos e Pesquisas Educacionais do Ministério da Educação (Inep) informando que escolas que usam computadores sem conexão à internet não ganham em desempenho, chegando a baixar suas médias em avaliações oficiais. 0 que melhora 0 aprendizado é o acesso à grande rede. De acordo com o levantamento realizado com base em dados do Sistema de Avaliação da Educação Básica (Saeb), ter computadores conectados à rede eleva em 5,6 pontos o resultado dos alunos. Por outro lado, simplesmente manter laboratórios de informática influencia negativamente os resultados, chegando a diminuir a média das escolas. "[Há] relação negativa entre a existência de laboratório de informática na escola e o desempenho escolar médio em matemática", afirmam as autoras da pesquisa. 0 estudo do Inep foi feito levando em conta turmas de $4^{a}$ sérdo ensino fundamental que fizeram as provas de matemática. Foram consideradas apenas as escolas que participaram do Saeb nas provas de 1999, 2001 e 2003. 
A entrada das Tecnologias de Informação e Comunicação (TIC), pelo portão da frente da escola, aliada a um projeto político-pedagógico comprometido com as reais necessidades da população poderia ter contribuído para o encurtamento das distâncias entre os incluídos e os excluídos; entre os letrados e aqueles que ficaram à margem do mundo das letras. Fica, assim, evidente que a educação e a mídia tanto podem representar a opressão quanto a emancipação. Para que se minimize este paradoxo, é necessário que a função da educação e o papel da mídia em nossa sociedade sejam constantemente reavaliados de forma critica. Só desta forma a inserção das TICs no cotidiano terá sentido e se constituirá num ganho para o processo ensino-aprendizagem e para o acesso democrático ao capital cultural produzido pela humanidade. Caso contrário, como tem sido constantemente visto, as políticas públicas para inserção de tecnologia no cotidiano escolar se tornam material de barganha eleitoreira a cada eleição, ou vão sendo rebatizadas para que cada governante possa imprimir seu ego em projetos faraônicos de compra de computadores.

Até hoje, mais de uma década depois da criação do Proinfo, continua-se sem saber exatamente quantas escolas têm ou não têm laboratórios de informática, e, se têm, com que tipo de computadores, com que tipo de acesso, enfim todo o detalhamento que seria necessário a quem tem realmente interesse na qualidade de ensino para além dos períodos eleitorais. Entretanto, é certo que, caso as metas tivessem sido plenamente atendidas, não haveria no ar a eterna promessa de informatizar e interligar todas as escolas públicas do país, e também não haveria ainda 14 milhões de analfabetos. É certo também que a qualidade da educação brasileira não depende apenas de sua informatização; entretanto, a informatização da educação tem sido uma plataforma das políticas governamentais desde o século passado - plataforma essa distante de ser atendida. Dessa forma, é possivel afirmar que nem quantitativamente falando e muitos menos qualitativamente a tecnologia contribuiu para a melhoria da qualidade de ensino no pais nas últimas décadas. Esta constatação ratifica resultados de pesquisas nacionais e internacionais que indicam que a simples existência de computadores nas escolas não se traduz em melhoria de desempenho escolar, embora o acesso a computadores e à internet seja muito valorizado pela sociedade e tenha alto impacto político (UNESCO, 2008a; UNESCO, 2008b).

No Decreto n 6.300 (BRASIL, 2007a, não paginado), o então Presidente da República afirma que "O Programa Nacional de Tecnologia Educacional - Proinfo, executado no âmbito do Ministério da Educação, promoverá o uso pedagógico das tecnologias de informação e comunicação nas redes públicas de educação básica."

Para promover a utilização do uso pedagógico das TICs, o Decreto (BRASIL, 2007a, não paginado) apresenta os seguintes objetivos: 
I - promover o uso pedagógico das tecnologias de informação e comunicação nas escolas de educação básica das redes públicas de ensino urbanas e rurais;

II - fomentar a melhoria do processo de ensino e aprendizagem com o uso das tecnologias de informação e comunicação;

III - promover a capacitação dos agentes educacionais envolvidos nas ações do Programa;

IV - contribuir com a inclusão digital por meio da ampliação do acesso a computadores, da conexão à rede mundial de computadores e de outras tecnologias digitais, beneficiando a comunidade escolar e a população próxima às escolas;

V - contribuir para a preparação dos jovens e adultos para o mercado de trabalho por meio do uso das tecnologias de informação e comunicação; e

VI - fomentar a produção nacional de conteúdos digitais educacionais.

0 atual Programa Nacional de Tecnologia Educacional (BRASIL, 2007a), o novo Proinfo, como pode ser visto pelos seus objetivos publicados, não difere muito do Programa Nacional de Informática na Educação, o Proinfo da década de 1990; resta saber se o atual conseguirá contribuir, de fato e de direito, para a tão proclamada melhoria da qualidade de ensino brasileiro. Diante de todo esse quadro de políticas públicas descontinuadas, de programas faraônicos e de resultados catastróficos, fica uma questão: entre índices, programas e computadores, como faremos para dar conta do analfabetismo, da baixa escolaridade, enfim, como colocar este pais em pé de igualdade com o desenvolvimento quando a temática é educação?

\section{Educação e tecnologia: para quê?}

As novas tecnologias estão influenciando o comportamento da sociedade contemporânea e transformando o mundo em que vivemos. Entretanto, é fato já comprovado que elas, desconectadas de um projeto pedagógico, não podem ser responsáveis pela reconstrução da educação no país, já que por mais contraditório que possa parecer, a mesma tecnologia que viabiliza o progresso e as novas formas de organização social também têm um grande potencial para alargar as distâncias existentes entre os mundos dos incluídos e dos excluídos.

No Brasil, como em tantos outros paises chamados emergentes, convive-se com diferentes categorias de analfabetismo: da escrita (da palavra), funcionais e tecnológicos. A existência de altos níveis de analfabetismo evidencia que ainda há muitas barreiras a serem ultrapassadas até que as já não tão novas mídias eletrônicas e o acesso e uso da informação tenham se tornado uma realidade no cotidiano escolar brasileiro. 
Como fica claro, a educação é apenas mais um indicador de fracasso, entre tantos outros, com que a sociedade brasileira precisa lidar. 0 que não se pode é reduzir o debate da qualidade da escola brasileira à questão da inserção ou não das mídias em seu cotidiano. Na verdade, o cerne da questão está no abismo existente entre o discurso oficial sobre a inserção de tecnologia na prática pedagógica e aquilo que é realmente oferecido na grande maioria das escolas. Mais do que aparelhar uma escola com toda a parafernália tecnológica deste início de século é preciso que se saiba o que fazer com ela para que não sejam repetidos os equivocos cometidos pelos modismos ocasionais ou pelos aproveitadores que, vampiristicamente, se alimentam da eterna crise da educação brasileira.

Por outro lado, é preciso enfrentar os desafios inerentes à educação formal brasileira de forma democrática, criativa, colaborativa com metas de médio e longo prazos e alcance em larga escala. Como afirma Moran (1998), "nunca tivemos tantas tecnologias fantásticas de comunicação e, ao mesmo tempo, é um desafio encontrar o ponto de equilibrio entre o deslumbramento e a resistência tão comuns entre muitos educadores." Resistência revelada tanto pelos resultados de inúmeras pesquisas quanto pelos mecanismos de defesa com relação ao enfrentamento das tecnologias por parte de um número significativo de professores de diferentes seguimentos em sua prática profissional.

Mas afinal, quem é professor brasileiro?

Parem de associar qualidade de educação com professor dentro de sala de aula. Porque não tem condição de ter qualidade em educação com professores tendo de multiplicar o que ganha trabalhando em três horários em sala de aula: $R \$ 930$ de manhã, $R \$ 930$ à tarde e $R \$ 930$ à noite.

(Fragmento do discurso da Professora Amanda Gurgel para os deputados da Assembleia Legislativa do Rio Grande do Norte em audiência pública, em 10 de maio de 2011)

Os resultados apresentados pela pesquisa 0 Perfil dos Professores Brasileiros (ANDRADE et al., 2004) realizada pela Unesco - em parceria com o Instituto Paulo Montenegro, o Inep e o MEC -, junto a mais de 5.000 professores de ensino fundamental e médio, de escolas públicas e privadas, dos 27 Estados brasileiros, revela que um terço dos professores brasileiros se classifica como pobre. Considerando-se as faixas salariais, $65,5 \%$ possuem renda familiar entre dois e 10 salários mínimos e $24 \%$ entre 10 e 20 salários mínimos. Os professores brasileiros têm dificuldades de acesso à tecnologia e à cultura. Mais de $40 \%$ dos entrevistados foram no máximo uma vez a museus, 23,5\% leem jornal somente uma ou duas vezes por semana, 58,4\% nunca usam a internet e 59,5\% não têm correio eletrônico. A maioria $(74,3 \%)$ tem como principal forma de lazer a televisão. Este quadro sugere que o uso da internet ainda é pouco significativo na vida dos professores brasileiros que estão incluídos no mundo cibernético. Portanto, a ausência deste hábito, por diferentes motivações - ideológi- 
cas, financeiras, de tempo, etc. -, reflete alguns ângulos da questão da subutilização do computador em sala de aula, na medida em que não haja um projeto pedagógico bem-estruturado que garanta uma práxis profissional efetivamente transformadora.

Para que a utilização de tecnologias no processo ensino-aprendizagem rompa as barreiras do tecnicismo e do modismo, é necessário se ter clareza das intenções e objetivos pedagógicos, ou seja, da intencionalidade das ideologias que estruturam os Projetos Pedagógicos e que determinam a práxis pedagógica. É preciso que os professores se apropriem da importância de seu papel social e tomem as rédeas do fazer pedagógico, trazendo para a sua prática tanto o novo quanto as mudanças necessárias para assimilá-lo de forma seletiva e crítica.

Estão me colocando dentro de uma sala de aula com um giz e um quadro para salvar o Brasil? Salas de aulas superlotadas com alunos entrando com carteira na cabeça porque não têm carteiras nas salas. Sou eu a redentora do país? Não posso, não tenho condições. Muito menos com o salário que recebo (GURGEL, 2011, não paginado).

0 primeiro passo é admitir que o "Rei está nu". E isto significa elaborar um rol de prioridades para que se possa elencar, de forma responsável, um plano de metas para a confecção da "roupa do rei". Para iniciar, o ponto crucial de qualquer programa do campo da educação é o professor. Nada acontecerá se não houver em sala de aula um profissional bem-formado, bem-pago, avaliado, motivado, com plano de carreira, enfim, com estes pequenos requisitos que normalmente atraem os sujeitos para esta ou aquela carreira, para além da dita vocação e do talento.

0 magistério não é algo que se faça por amor, já chega da "Pedagogia do Amor", vive-se em momentos de competência e eficiência. Que carreira de nível universitário atrairia um jovem cujo salário fosse $R \$ 607,26$ (16 horas)? Este foi o salário divulgado na mídia e no Edital do Concurso para Professores do Estado do Rio de Janeiro (mais recente concurso público), em outubro de 2008, para o preenchimento de 15 mil vagas. Que sujeitos são atraídos para uma carreira com esta remuneração? Que cursos vêm sendo oferecidos para esta clientela? Até que ponto os cursos de Formação de Professores atendem as reais necessidades cotidianas das escolas e de seus atores? É certo que a grande maioria dos cursos oferecidos, tanto em nível médio quanto em nível universitário, está longe de atender as demandas da atual prática pedagógica, com ou sem tecnologia. Para ilustrar, a maioria das Instituições de Ensino Superior no país, ao abrirem seus primeiros cursos, normalmente optam pelas Licenciaturas e pela Pedagogia, pois são os cursos de mais baixo investimento, pois não demandam laboratórios e as exigências do Inep para a avaliação são as mais simples. Por que será? A quem interessa formar professores em cursos baratos e, por conseguinte, de baixa qualidade? Acho que agora se começa a tangenciar o cerne do fracasso de nossa educação. 
Nenhum Governo deveria abrir um concurso para professores com nível universitário e oferecer menos de um salário mínino e meio de remuneração. Nenhum Governo deveria insistir em não exigir nível universitário para seus professores das primeiras séries do ensino fundamental. Nenhum Governo deveria festejar um piso salarial de $R \$ 950,00$ para professores das primeiras séries do ensino fundamental e não enfrentar as posições dos Governos estaduais e municipais que já afirmaram não ter condições para bancar o que eles chamam de ônus.

Seria possivel continuar enumerando uma sérde outras razões pelas quais, apesar dos inúmeros programas voltados para a inserção de tecnologia no cotidiano escolar, nenhum deles tem, de maneira geral, contribuido para a efetiva melhoria da qualidade de ensino no país. Das difíceis relações de poder que se estabelecem nas escolas que ganham laboratórios, das chaves dos laboratórios que só alguns "amigos do Rei" têm acesso, a uma sérde outros indicadores comportamentais que revelam a mediocridade que permeia o cotidiano escolar e que se constituem em obstáculos à plena utilização de computadores por alunos e professores em suas rotinas escolares, assim como das frequentes promessas políticas, a Educação no país ainda está abaixo da média da Organização para Cooperação e Desenvolvimento Econômico (OCDE), formada por grupo de paises mais avançados e por orientais. 0 primeiro discurso da atual presidente do país, feito em cadeia de rádio e tevê no início do ano letivo, destaca a importância da educação: "Estou aqui para reafirmar o meu compromisso com a melhoria da educação e convocar todos os brasileiros e brasileiras para lutarmos juntos por uma educação de qualidade" (informação verbal). Entretanto, o corte do Orçamento divulgado logo em seguida a posse não poupou o MEC, que contribuiu com R $\$ 3$ bilhões, ficando assim evidente que, de fato, os discursos mascaram a seguinte verdade: em nenhum governo a educação é prioridade.

As evidências já apresentadas são mais que suficientes para se entender o fracasso. No que diz respeito à Formação de Professores, pode afirmar-se que ela é absolutamente anacrônica; os pisos salariais são aviltantes; não há, na maioria das secretarias públicas estaduais e municipais, planos de carreira adequados à profissão com níveis de ascensão por formação e tempo de serviço.

Com relação à tecnologia, os programas ganham novos nomes, novas roupagens, mas continuam os mesmos. No que tange ao curriculo, as mudanças curriculares são feitas sem a efetiva participação dos professores, o que as torna inúteis e não cumpridas.

Só quem está em sala de aula e pega três ônibus por dia para chegar em seu local de trabalho é que pode falar com propriedade sobre isso. Fora isso, qualquer colocação que seja feita aqui é apenas para mascarar uma verdade: em nenhum governo, em nenhum momento a educação foi uma prioridade (GURGEL, 2011, não paginado). 
A fala da professora reflete, de forma inequívoca, o atual cotidiano da rotina de professores no pais. Embora o discurso tenha acontecido na Assembleia Legislativa do Rio Grande do Norte, ele poderia ter acontecido em qualquer outra do pais, já que o quadro não difere muito entre os estados, quando o assunto é a precariedade da carreira de magistério.

Sempre o que o poder solicita da gente é paciência, é tolerância... Vocês nos pedem paciência, a minha necessidade de alimentação é imediata, a minha necessidade de transporte é imediata, a necessidade de Jéssica de ter uma educação de qualidade é imediata [...] (GURGEL, 2011, não paginado).

Em resposta ao discurso da professora Amanda, a atual secretária afirmou que

Nós secretários de estado conversamos com Fernando Haddad (ministro da Educação) no mês passado falando dessas questões que afligem os estados. Precisamos saber como podemos fazer uma revolução na educação pública. Estamos reestruturando a secretaria, investindo na parte pedagógica. Mas temos muitas escolas em situação precária. 0 problema é da educação pública nacional. Aqui temos escolas que funcionam muito bem e escolas que precisam avançar muito. Podemos dizer que o salário dela está acima do piso nacional para 30 horas, que é de $R \$ 890$. É preciso construir uma carreira docente que coloque professores no mesmo pé de igualdade dos demais profissionais. Mas isto é uma trajetória longa (DISCURSO..., 2011, não paginado).

A resposta da Secretária apenas ratifica a angústia vivida pelos professores a quem sempre são solicitadas doses de paciência e tolerância, como se isso ainda fosse possivel no atual quadro que se enfrenta. Por outro lado, nas entrelinhas do discurso evasivo, fica a indicação de que a culpa pelo fracasso é exclusiva das escolas que não funcionam bem, ou seja, do professor. Dessa forma, o fracasso escolar acaba sendo sempre fruto da ação do professor, retirando do estado uma sérde responsabilidades que antecedem a ação pedagógica.

\section{Investimento no Professor: a única saída}

Todos os anos são gastas fortunas em avaliações de desempenho dos alunos e dos sistemas, e não se percebe o que é feito para minimizar os problemas apresentados pelos inúmeros relatórios técnicos apresentados contendo os resultados das referidas avaliações. Fato é que, com ou sem tecnologia, há décadas o Brasil tem sido campeão quando o assunto é falta de qualidade de ensino.

Não é novidade que todos já sabem o que é possivel fazer com as TICs em sala de aula. Também já se sabe que elas forçaram os portões das escolas, entraram e 
continuarão entrando, mesmo que seja para virar "totem" ou para revelar as perversas e rançosas relações de poder que permeiam os ambientes escolares. Fica evidente que algumas escolas vestiram roupa nova, mas não propiciaram qualquer mudança de fato em sua prática pedagógica; e o rei continua nu.

Para melhorar a qualidade da educação, não basta avaliar o aluno. A saída é investir no professor. Melhorar os salários, melhorar a formação, melhorar as condições de trabalho. Professor precisa ser formado em serviço, trabalhando, mas, antes de tudo, é preciso que o salário seja compatível com o seu nível de formação e atuação para poder atrair pessoas para o magistério. É fundamental que haja muito mais investimentos na educação. É uma questão de sobrevivência da própria sociedade como um todo.

Entretanto, fica dificil acreditar em mudanças quando, no que concerne à formação de professores, o que se pode verificar é um fazer e refazer de portarias, decretos, regulamentos e leis, assim como uma sérde outros descumprimentos legais históricos. Só para exemplificar, em 1996, a Lei 9394(BRASIL, 1996) em seu Título VI - Dos Profissionais da Educação, no artigo 62 postulava que

A formação de docentes para atuar na educação básica farse-á em nível superior, em curso de licenciatura, de graduação plena, em universidades e institutos superiores de educação, admitida, como formação mínima para o exercício do magistério na educação infantil e nas quatro primeiras séries do ensino fundamental, a oferecida em nível médio, na modalidade Normal.

Entretanto, para que o artigo 62 fosse cumprido, foi necessária sua regulamentação, pelo Decreto nº 3.276 (BRASIL, 1999), com a seguinte redação:

\$2 ${ }^{\circ}$ A formação em nível superior de professores para a atuação multidisciplinar, destinada ao magistério na educação infantil e nos anos iniciais do ensino fundamental, far-se-á, preferencialmente, em cursos normais superiores.

$\S 3^{\circ}$ Os cursos normais superiores deverão necessariamente contemplar áreas de conteúdo metodológico, adequado à faixa etária dos alunos da educação infantil e dos anos iniciais do ensino fundamental, incluindo metodologias de alfabetização e áreas de conteúdo disciplinar, qualquer que tenha sido a formação prévia do aluno no ensino médio.

A redação final deste Decreto só foi apresentada no Decreto n 3.554 (BRASIL, 2000, p. 1), com o seguinte texto: 
Art. $1^{\circ} 0 \S 2^{\circ}$ do art. $3^{\circ}$ do Decreto $n^{\circ} 3.276$, de 6 de dezembro de 1999, passa a vigorar com a seguinte redação:

"§ $2^{\circ} \mathrm{A}$ formação em nível superior de professores para a atuação multidisciplinar, destinada ao magistério na educação infantil e nos anos iniciais do ensino fundamental, farse-á, preferencialmente, em cursos normais superiores." (NR) Art. $2^{\circ}$ Este Decreto entra em vigor na data de sua publicação. Brasilia, 7 de agosto de $2000 ; 179^{\circ}$ da Independência e $112^{\circ}$ da República.

A criação dos Institutos Superiores enfrentou grande resistência das universidades e dos centros universitários, instituições que tinham autonomia para gerir seus cursos. Em agosto de 2000, depois de muita pressão, foi publicado outro decreto, substituindo o termo "exclusivamente" por "preferencialmente" - o que permitia que a formação de professores de séries iniciais não precisasse ser feita unicamente nos institutos. As instituições com autonomia criaram habilitações em pedagogia para formar professores para as séries iniciais e, assim, não tiveram que criar outro curso para atender a esta demanda.

As demais instituições de ensino superior, faculdades, faculdades integradas e faculdades isoladas sem autonomia, deveriam investir nos institutos e no normal superior se quisessem formar professores de séries iniciais. 0 curso de pedagogia ficou direcionado não àqueles que queriam ser professores das séries iniciais (infantil e $1^{\mathrm{a}}$ à $4^{\mathrm{a}}$ ), mas sim para aos que tinham interesse em lecionar da 5 a à 8a série, ser um teórico da educação ou assumir um cargo de gestão (administrador, inspetor, supervisor, diretor ou orientador pedagógico). 0 curso de pedagogia ficou associado a uma profissão não docente.

Talvez em função da resistência das instituições em criar os cursos normais superiores, além da inserção da palavra "preferencialmente" em vez de "obrigatoriamente", tenham sido determinantes para que o MEC extinguisse os cursos normais superiores do pais, em abril de 2006. De acordo com as diretrizes do MEC, a partir de então, quem quisesse se tornar professor de turmas da educação infantil (préescola) e da $1^{a}$ à $4^{a}$ sérprecisaria estudar pedagogia. 0 curso de pedagogia deveria ser, assim, reformulado mais uma vez para atender as novas diretrizes.

Desta forma, por meio do Parecer CNE/CP no 5/2005 (CONSELHO NACIONAL DE EDUCAÇÃO, 2006a) e da Resolução CNE/CP n. 1 (CONSELHO NACIONAL DE EDUCAÇÃO, 2006b), são consubstanciadas as Diretrizes Curriculares Nacionais para o Curso de Pedagogia (DCN Pedagogia). As DCN Pedagogia definem a sua destinação, sua aplicação e a abrangência da formação a ser desenvolvida nesse curso. São destinadas: a) à formação inicial para o exercício da docência na educação infantil e nos anos iniciais do ensino fundamental; b) aos cursos de ensino médio de modalidade normal e em cursos de educação profissional; c) na área de serviços e apoio escolar; d) em outras áreas nas quais sejam previstos conhecimentos pedagógicos. 
A formação passará a abranger, integradamente à docência, a participação da gestão e avaliação de sistemas e instituições de ensino em geral, a elaboração, a execução, o acompanhamento de programas e as atividades educativas (CONSELHO NACIONAL DE EDUCAÇÃO, 2006a, p. 6).

As DCN-Pedagogia trazem para o cenário educacional um amplo debate sobre a formação e atuação profissional dos pedagogos. Tal perspectiva é reforçada nos artigos $4^{\circ}$ e $5^{\circ}$ da Resolução CNE/CP n. 1 (CONSELHO NACIONAL DE EDUCAÇÃO, 2006b), que definem a finalidade do curso de pedagogia e as aptidões requeridas do profissional desse curso:

Art. $4^{\circ}$ - 0 curso de Licenciatura em pedagogia destina-se à formação de professores para exercer funções de magistério na Educação Infantil e nos anos iniciais do Ensino Fundamental, nos cursos de Ensino Médio, na modalidade Normal, de Educação Profissional, na área de serviços e apoio escolar e em outras áreas nas quais sejam previstos conhecimentos pedagógicos.

Parágrafo único. As atividades docentes também compreendem participação na organização e gestão de sistemas e instituições de ensino, englobando:

I - planejamento, execução, coordenação, acompanhamento e avaliação de tarefas próprias do setor da Educação;

II - planejamento, execução, coordenação, acompanhamento e avaliação de projetos e experiências educativas não-escolares;

III - produção e difusão do conhecimento científico-tecnológico do campo educacional, em contextos escolares e não-escolares.

A docência nas DCN-Pedagogia não deveria ficar restrita ao ato de ministrar aulas. 0 sentido da docência é ampliado, uma vez que a ela é integrada a ideia de trabalho pedagógico, a ser desenvolvido em espaços escolares e não escolares, assim, sintetizado no Parecer CNE/CP nº 5 (CONSELHO NACIIONAL DE EDUCAÇÃO, 2006a, p. 7):

Entende-se que a formação do licenciado em pedagogia fundamenta-se no trabalho pedagógico realizado em espaços escolares e não-escolares, que tem a docência como base. Nesta perspectiva, a docência é compreendida como ação educativa e processo pedagógico metódico e intencional, construído em relações sociais, étnico-raciais e produtivas, as quais influenciam conceitos, princípios e objetivos da pedagogia.

Dessa forma, a docência, tanto em processos educativos escolares como não escolares, não se confunde com a utilização de métodos e técnicas pretensamente pedagógicos, descola- 
dos de realidades históricas específicas. Constitui- se na confluência de conhecimentos oriundos de diferentes tradições culturais e das ciências, bem como de valores, posturas e atitudes éticas, de manifestações estéticas, lúdicas, laborais.

Como se pode perceber, há aspectos contraditórios entre os Cursos de pedagogia e o extinto curso normal superior. As novas Diretrizes para os cursos de pedagogia, recentemente convalidadas por portaria do MEC, foram formuladas com óbvio intuito de destruir os cursos normais superiores que vêm se multiplicando no país na área privada, já que o setor público os rechaçou de forma radical. Foi assim destruída uma nova experiência, sem o tempo adequado para avaliação. De certa forma, também representou um "golpe" porque passou por cima da legislação, pretendendo que uma mera portaria invalidasse determinações explícitas da lei maior da educação brasileira, a LDB (BRASIL, 1996).

Em 2010, no site da Coordenação de Aperfeiçoamento de Pessoal de Nível Superior (Capes) é possivel ler o seguinte texto:

A formação de professores para atuar na educação básica deverá ser de nível superior, em curso de licenciatura, de graduação plena, em universidades e institutos superiores de educação. É o que diz o Projeto de Lei da Câmara (PLC) 280/09, que exige formação de nível superior para os professores da educação básica (educação infantil, ensino fundamental e médio). De iniciativa do presidente da República, o projeto altera a Lei 9.394/96, que estabelece as diretrizes e bases da educação nacional (LDB)

0 Congresso retomou os trabalhos nesta terça-feira, 2, e o projeto tramita na Casa em regime de urgência. A pauta do Senado Federal está trancada enquanto o PLC 280/09 não for votado, entre outras propostas.

A Coordenação de Aperfeiçoamento de Pessoal de Nível Superior (Capes) já havia participado de uma audiência pública na Câmara dos Deputados em setembro de 2009 para debater sobre o tema. Pelo PLC, a formação de docentes para atuar na educação básica deverá ser de nível superior, em curso de licenciatura, de graduação plena, em universidades e institutos superiores de educação.

De acordo com a proposta, será admitida, no entanto, a contratação de professores com formação mínima de nível médio para a educação infantil e as quatro séries iniciais do ensino fundamental, onde não existirem, comprovadamente, professores com nível superior. Essa proposta foi feita pela Câmara, que aprovou a matéria na forma de substitutivo.

0 ministro da Educação, Fernando Haddad, disse, na mensagem enviada ao Legislativo, que a proposição pretende "ele- 
var a formação mínima exigida para docentes que atuem no ensino fundamental". A formação de nível médio, na modalidade normal, passaria, segundo o ministro, a ser admitida apenas para os professores que atuam na educação infantil (PROJETO..., 2010, não paginado, grifo do autor).

Quase duas décadas depois de promulgada a LDB (BRASIL, 1996) parece que se volta à estaca zero, ou seja, se percebe que é fundamental para a qualidade de ensino a qualidade de formação do professor. Entretanto, mais uma vez, se garante por lei também "a contratação de professores com formação mínima de nível médio para a educação infantil e as quatro séries iniciais do ensino fundamental, onde não existirem, comprovadamente, professores com nivel superior." Isto mostra a total descontinuidade das políticas públicas no setor educacional ou, mais ainda, até que ponto é interessante para determinados setores da sociedade manter o fracasso educacional brasileiro como moeda de troca política, ou colocar o professor como o grande vilão do fracasso escolar?

\section{Considerações finais}

Embora não tenha sido o foco deste estudo tangenciar as reflexões que atravessam as raízes ideológicas das Diretrizes Nacionais para o Curso de Pedagogia ou os motivos que levaram à extinção dos cursos normais superiores, seria impossivel tecer qualquer análise sobre a inserção de tecnologia no cotidiano escolar limitando-a ao quantitativo de máquinas adquiridas ou à montagem de laboratórios em unidades escolares. A utilização pedagógica da informática depende, sim, de computadores e laboratórios, isso é óbvio; mas depende, principalmente, do papel do professor. Portanto, cabe a questão: que professor o pais está formando para atuar em suas escolas, estejam elas equipadas ou não? Aliás, como mostram as estatísticas, estão longe de atingir as metas no que concerne a laboratórios de informática. Não é novidade que a educação poderia ter contribuído de forma importante para a construção de um novo modelo social em uma sociedade "emergente" como a brasileira. Um modelo que privilegiasse a interação entre as diferentes linguagens, a produção do conhecimento, a crítica, a interação social, a comunicação, o espaço para a criação de uma sociedade mais justa e menos excludente, a sustentabilidade do planeta, a cooperação, a ética - enfim, a consciência crítica necessária para mudanças significativas. Entretanto, a escola brasileira que se tem hoje, como comprovado por grande parte das pesquisas, é uma escola que vem perpetuando os indices do fracasso, do tradicionalismo e do conservadorismo, contribuindo em larga escala para a exclusão social, ao deixar de cumprir o seu papel de educar o cidadão, garantindo não só o acesso universal, mas uma educação de qualidade, para além dos rankings a todos os cidadãos brasileiros.

As políticas públicas de informatização do cotidiano escolar não atingiram suas metas, os programas de erradicação do analfabetismo ainda enfrentam o desafio de 14 milhões de analfabetos, o programa de formação de professores, assim como as ações 
de formação continuada da categoria, também não têm contribuído para garantir tanto a qualidade de ensino quanto uma carreira atraente para jovens deste início de século. Portanto, o que de fato existe é uma escola que, embora pudesse ter tido um papel prioritário rumo ao caminho do sucesso, não ousou vencer as barreiras do conservadorismo e da mesmice. Não assumiu que o Rei está, de fato, nu e não teve competência para vesti-lo adequadamente como demanda a sociedade contemporânea.

\section{Referências}

ABRANCHES, S. P. Modernidade e formação de professores: a prática dos multiplicadores dos Núcleos de Tecnologia Educacional do Nordeste e a informática na educação. 2003. 278 f. Tese (Doutorado em Educação) Universidade de São Paulo, São Paulo, 2008.

ANDRADE, E. R. et al. 0 perfil dos professores brasileiros: o que fazem o que pensam, o que almejam. Brasília, DF: UNESC0; São Paulo: Moderna, 2004.

BARROS, R. P.; HENRIQUES, R.; MENDONÇA, R. Education and equitable economic development. Economia, v. 1, n. 1, p. 111-144, jan. 2000.

BRASIL. Decreto n. 3.276, de 6 de dezembro de 1999. Dispõe sobre a formação em nível superior de professores para atuar na educação básica, e dá outras providências. Diário Oficial [da] República Federativa do Brasil, Brasília, DF, 7 dez. 1999.

. Decreto $n^{\circ}$. 3.554, de 7 de agosto de 2000. Dá nova redação ao $§ 2^{\circ}$ do art. $3^{\circ}$ do Decreto $n^{\circ} 3.276$, de 6 de dezembro de 1999, que dispõe sobre a formação em nivel superior de professores para atuar na educação básica. Diário Oficial da União, Brasilia, DF, 8 ago. 2000. Seção 1, p. 1.

. Decreto $n^{\circ}$. 6.300, de 12 de dezembro de 2007. Dispõe sobre o Programa Nacional de Tecnologia Educacional -Prolnfo. Diário Oficial da União, Brasília, DF, 13 dez. 2007a. Disponível em: <http://www.planalto.gov.br/ccivil_03/ _Ato2007-2010/2007/Decreto/D6300.htm>. Acesso em: 27 jul. 2009.

BRASIL. Lei nº. 9.394, de 20 de dezembro de 1996. Estabelece as diretrizes e bases da educação nacional. Diário Oficial [da] República Federativa do Brasil, Brasília, DF, 23 dez. 1996.

Lei $n^{\circ}$ 9.472, de 16 de julho de 1997. Dispõe sobre a organização dos serviços de telecomunicações, a criação e funcionamento de um órgão regulador e outros aspectos institucionais, nos termos da Emenda Constitucional no 8, de 1995. Diário Oficial [da] República Federativa do Brasil, Brasilia, DF, 17 jul. 1997c. 
BRASIL. IDEB. Brasilia, DF, 2010. Disponivel em: < http://portal.mec.gov.br/>. Acesso em: mar. 2010.

- Ministério da Educação. Plano de Desenvolvimento da Educação: razões, princípios e programas. Brasília, DF, 2007b. Disponível em: <http://www.dominiopublico.gov.br/download/texto/me004370.pdf > . Acesso em: mar. 2010.

. Ministério da Educação e do Desporto. Portaria n 522, de 9 de abril de 1997. Domínio Público, Brasília, DF, 1997b. Disponível em: <http:// www.dominiopublico.gov.br/download/texto/me001167.pdf>. Acesso em: mar. 2010.

- Ministério da Educação e do Desporto. Secretaria de Educação a Distância. Programa Nacional de Informática na Educação: Prolnfo: diretrizes. Brasília, DF, 1997a. Disponível em: <http://www.dominiopublico.gov.br/ download/texto/me001166.pdf>. Acesso em: 27 jul. 2011.

- Prolnfo: Programa Nacional de Informática na Educação: recomendações gerais para a preparação dos Núcleos de Tecnologia Educacional (versão julho 1997). Brasília, DF, jul. 1997b. Disponível em: <http:// www.dominiopublico.gov.br/download/texto/me001168.pdf>. Acesso em: 27 jul. 2011.

BUZATO, M. Letramento digital abre portas para o conhecimento. EducaRede, [S. I., 2003]. Disponível em:

<http://www.educarede.org.br/educa/html/index_busca.cfm>. Acesso em: 12 mar. 2010.

CABRAL FILHO, A. V. Sociedade e tecnologia digital: entre incluir ou ser incluida. Liinc em Revista, Rio de Janeiro, v. 2, n. 2, set. 2006. Disponível em: <http:// www.ibict.br/liinc>. Acesso em: 27 jul. 2011.

CAMPOS, S. S. Mapeamento da informática educativa nas escolas municipais de Jaraguá do Sul/SC. 2004. 154 f. Dissertação (Mestrado em Educação)Universidade Regional de Blumenau, Blumenau, SC, 2004.

CASTELLS, M. Sociedade em rede: a era da informação; economia, sociedade e cultura. São Paulo: Paz e Terra, 1999.

CONSELHO NACIONAL DE EDUCAÇÃO (Brasil). Conselho Pleno. Parecer CNE/CP $\mathrm{n}^{\circ}$. 5, de 13 de dezembro de 2005. Diário Oficial da União, Brasília, DF, 15 maio $2006 a$. 
CONSELHO NACIONAL DE EDUCAÇÃO (Brasil). Resolução CNE/CP nº 1, de 15 de maio de 2006. Institui Diretrizes Curriculares Nacionais para o Curso de Graduação em Pedagogia, licenciatura. Diário Oficial da União, Brasília, DF, 16 maio 2006b. Seção 1, p. 11.

CYSNEIROS, P. G. Programa Nacional de Informática na Educação: novas tecnologias, velhas estruturas. In: BARRETO, R. G. (Org.). Tecnologias educacionais e educação a distância: avaliando políticas e práticas. Rio de Janeiro: Quartet, 2003.

DEMO, P. Inclusão digital: cada vez mais no centro da inclusão social. Inclusão Social, Brasília, DF, v. 1, n. 1, p. 36-38, out./mar. 2005. Disponível em: <http:// www.ibict.br/revistainclusaosocial/viewarticle.php?id=4>. Acesso em: 27 jul. 2011.

DISCURSO de professora vira hit na web e ganha apoio de secretária do RN. Painel Político, Porto Velho, 2011. Disponível em: <http:// www.painelpolitico.com/Editorias/Noticias/Discurso-de-professora-vira-hit-naweb-e-ganha-apoio-de-secretaria-do-RN.html>. Acesso em: 21 maio 2011.

FERNANDES, E. Implicações metodológicas do uso de tecnologias da comunicação e da informação: o caso Proinfo em Dourados-MS. 2003. 137 f. Dissertação (Mestrado em Engenharia de Produção)-Universidade Federal de Santa Catarina, Florianópolis, SC, 2003.

FISHLOW, A. Distribuição de renda no Brasil: um novo exame. Dados: revista de Ciências Sociais, Rio de Janeiro, n. 11, 1973.

GURGEL, A. Professora Amanda Gurgel discursa para deputados do RN. You Yube, Natal, 10 maio 2011. Disponivel em: <http://www.youtube.com/ watch?v=HdALIE_WhOU>. Acesso em: 27 jul. 2011.

HOBOLD, C. H. Atuação do Núcleo de Tecnologia Educacional e a realidade educativa contemporânea. 2002. 68 f. dissertação (Mestrado em Engenharia de Produção)-Universidade Federal de Santa Catarina, Florianópolis, SC, 2002.

HOFFMANN, R. Mensuração da desigualdade e da pobreza no Brasil. In: HENRIQUES, R. (Org.). Desigualdade e pobreza no Brasil. Rio de Janeiro: Ipea, 2000.

IBGE. Censo Demográfico 2010. Rio de Janeiro, 2011. Disponível em: <http:// www.censo2010.ibge.gov.br/>. Acesso em: 27 jul. 2011. 
IBGE. Pesquisa Nacional por Amostra de Domicilio: PNAD 2007. Rio de Janeiro, 2007. < http://www.ibge.gov.br/>. Acesso em: 20 mar. 2010.

INEP. Censo Escolar 2010. Brasília, DF, 2010.

IPEA. Análise e recomendações para as políticas públicas de massificação de acesso à internet em banda larga. Comunicados do Ipea, Brasília, DF, n. 46, 26 abr. 2010a. Disponível em: <http://www.ipea.gov.br/portal/images/stories/PDFs/ comunicado/ 100426_comunicadoipea46.pdf>. Acesso em:

PNAD 2009: primeiras análises: tendências demográficas. Comunicados do Ipea, Brasília, DF, n. 64,. 13 out. 2010b. Disponível em: <http:// www.ipea.gov.br/portal/images/stories/PDFs/comunicado/ 101013_comunicadoipea64.pdf>. Acesso em: mar. 2010.

LANGONI, C. G. Distribuição da renda e desenvolvimento econômico do Brasil. Rio de Janeiro: Expressão e Cultura, 1973.

MORAES, R. A. A política educacional de informática na educação brasileira e as influências do Banco Mundial: do formar ao Proinfo: 1987-2005. In: SEMINÁRIO NACIONAL DE ESTUDOS E PESQUISAS, 7., 2006, Campinas. Atas...Campinas, SP: HISTEDBR, 2006. Disponível em: <http://www.comunidadeproinfo.escolabr.com/ leitura/raquel_moraes/Raqueldealmeidamoraes_histedbr2006.pdf>. Acesso em: 27 jul. 2011.

MORAN, J. M. Mudanças na comunicação pessoal: gerenciamento integrado da comunicação pessoal, social e tecnológica. São Paulo: Paulinas, 1998.

NEY, M. G. Educação e desigualdade de renda no meio rural brasileiro. 2006. 21 f. Tese (Doutorado em Economia)-Instituto de Economia, Universidade Estadual de Campinas, Campinas, SP, 2006.

NEY, M. G.; SOUZA, P. M.; PONCIANO, N. J. Desigualdade de acesso à educação e evasão escolar entre ricos e pobres no Brasil rural e urbano. Revista Cientifica internacional, ano 3, n. 13, maio/jun. 2010.

OLIVEIRA, E. N. A utilização dos laboratórios de informática do Proinfo em escolas de Dourados - MS. 2001. 109 f. Dissertação (Mestrado em Engenharia de Produção) - Universidade Federal de Santa Catarina, Florianópolis, 2001.

PARAGUASSÚ, L. Computador nas escolas só dá resultado com internet, diz estudo. O Estado de S. Paulo, São Paulo, 7 nov. 2007. 
PASSOS, M. S. C. Uma análise crítica sobre as políticas públicas de educação: a concretização dos NTE em Salvador-Bahia. 2006. 181 f. Dissertação (Mestrado em Educação e Contemporaneidade)-Universidade do Estado da Bahia, Salvador, 2006.

PROJETO que exige nivel superior para professores será votado pelo Senado. Capes, Brasilia, DF, 2 fev. 2010. Disponivel em: <http://www.capes.gov.br/ servicos/sala-de-imprensa/36-noticias/3559-projeto-que-exige-nivel-superiorpara-professores-sera-votado-pelo-senado>. Acesso em: mar. 2010.

QUARTIERO, E. M. As tecnologias da informação e comunicação no espaço escolar: o Programa Nacional de Informática na Educação (Proinfo) em Santa Catarina. 2002. 253 f. Tese (Doutorado em Engenharia da Produção) Universidade Federal de Santa Catarina, Florianópolis, SC, 2002.

RAMOS, L.; VIEIRA, M. Desigualdade de rendimentos no Brasil nas décadas de 80 e 90: evolução e principais determinantes. Rio de Janeiro: IPEA, 2001. (Texto para discussão, n. 803). Disponivel em: <http://www.ipea.gov.br/pub/td/2001/ td_0803.pdf>. Acesso em:27 jul. 2011.

RELATÓRIO da Unesco diz que Brasil tem baixos índices na educação básica. Folha.com, São Paulo, 19 jan. 2010. Disponivel em:

< www1.folha.uol.com.br/folha/.../ult305u681846.shtml>. Acesso em: mar. 2010.

REZENDE, L. V. R. 0 processo de alfabetização em informação inserido em projetos de inclusão digital: uma análise crítica. 2005. Dissertação (Mestrado em Ciência da Informação)-Universidade de Brasilia, Brasília, DF, 2005.

RONSANI, I. L. Informática na educação: uma análise do Proinfo UnC. HISTEDBR On-line, Campinas, SP, n.19, 2005. Disponivel em: <http:// www.histedbr.fae.unicamp.br/art8_16.pdf>. Acesso em: fev. 2010.

SALAZAR, R. O Programa Nacional de Informática na Educação - Proinfo - em Santa Catarina: uma análise sociotécnica das capacitações (2002-2004). 2005. 130 f. Dissertação (Mestrado em Sociologia Política)-Universidade Federal de Santa Catarina, Florianópolis, SC, 2005.

SILVA, J. C. O Programa Nacional de Informática na Educação (Proinfo) e o desafio da inclusão digital: um estudo de caso do Proinfo/NTE - Niterói. 2005. 170 f. Dissertação (Mestrado em Políticas Sociais)-Universidade Federal Fluminense, Niterói, 2005.

SILVA, V. L. Informática na Educação: possibilidades de inclusão digital. 2007. Dissertação (Mestrado em Educação)-Universidade do Oeste de Santa Catarina, Joaçaba, SC, 2007. 
SILVEIRA, S. A. Exclusão digital: a miséria na era da informação. São Paulo: Fundação Perseu Abramo, 2001.

SORJ, B.Brasil@povo.com: a luta contra a desigualdade na sociedade da informação. Rio de Janeiro: Jorge Zahar; Brasilia, DF: Unesco, 2003.

SOUZA, C. B. Crianças e computadores: discutindo o uso das Tecnologias de Informação e Comunicação a Educação Infantil. 2003. 95 f. Dissertação.

(Mestrado)-Engenharia de Produção e Sistemas, Universidade Federal de Santa Catarina, Florianópolis, SC, 2003.

UEDA, M. E. Educação e rendimentos: uma abordagem econométrica. 2001.181f. Tese (Mestrado em Economia)-Instituto de Economia, Universidade Estadual de Campinas, Campinas, SP, 2001.

UNESCO. Computador na escola: o futuro anunciado. Revista TICS nas Escolas, [S. I.], v. 3, n. 2, 2008a.

. Computador na escola: tecnologia e aprendizagem. Revista TICs nas Escolas, [S. I.], v. 3, n. 3, 2008 b. Monitoramento de Educação para Todos 2010. Brasília, DF: Unesco, 2010.

Recebido em: 05/07/2010

Aceito para publicação em: 04/06/2011 